\title{
Mencari Definisi Kehadiran Antar-Subjek yang Bermakna di Ruang Digital
}

Binsar Jonathan Pakpahan

Sekolah Tinggi Filsafat Teologi Jakarta

b.pakpahan@stftjakarta.ac.id

\section{D01: https://doi.org/10.34307/b.v4i1.219}

Abstract: We need to re-define what is presence, especially in the frequent use of digital rooms and encounters during the Covid-19 pandemic. The article argues that meaningful presence in the digital rooms could be understood through Martin Heidegger idea in the metaphysics of presence and and Jacques Derrida's critique on it. Heidegger states that Dasein must think and analyze his or her thrownness in the world presence, so the presence is not an accidental event. Dasein also builds a relationship with other Dasein. Meanwhile, through the critique of the metaphysics of presence Derrida helps us to understand the signs and traces of presence that comes to us in his discussion on speech and text. By constructing an imagined discussion between both philosophers in the context of our question, the article will build an argument that meaningful presence between subjects can be achieved in the digital space.

Keywords: Martin Heidegger, Jacques Derrida, metaphysics of presence, digital room, presence

Abstrak: Dalam penggunaan pertemuan di ruang digital yang menjadi salah satu mode pertemuan di masa pandemi Covid-19, perlu untuk memberi definisi ulang mengenai apa itu kehadiran. Makalah ini akan berargumen bahwa kehadiran yang bermakna di ruang digital bisa dipahami melalui lensa berpikir metaphysics of presence yang diajukan oleh Martin Heidegger dan kritik terhadap metaphysics of presence dari Jacques Derrida. Heidegger mengatakan bahwa kehadiran tidak boleh menjadi sebuah proses yang tidak sengaja dan harus menjadi relasi yang membuat Dasein (subjek) menyadari keterlemparannya dalam ruang dan waktu. Melalui kritiknya atas metaphysics of presence Derrida akan membuat diri menyadari akan tanda dan jejak kehadiran yang datang kepada kita dalam pembahasannya mengenai speech (ucapan) dan text (teks). Melalui konstruksi pemikiran keduanya, tulisan ini akan membangun sebuah argumen bahwa kehadiran antar-subjek yang bermakna bisa dicapai dalam ruang digital.

Kata Kunci: Martin Heidegger, Jacques Derrida, metaphysics of presence, ruang digital, kehadiran. 
$\begin{array}{llll}\text { Article History : } & \text { Received: 27-01-2021 } & \text { Revised: 14-06-2021 } & \text { Accepted: 14-06-2021 }\end{array}$

\section{Pendahuluan}

Dalam Pandemi Covid-19, kita dihadapkan pada beberapa tantangan terbaru mengenai kehidupan peribadahan dan cara berinteraksi satu dengan yang lain. Penulis masih ingat ketika ibadah di beberapa gereja arus tengah di Indonesia harus memindahkan ibadahnya ke ruang digital ${ }^{1}$ (dalam bentuk live atau rekaman, di media Whatsapp, YouTube, Facebook, atau Instagram), perdebatan utama adalah apakah kita sedang hadir dalam ibadah tersebut? ${ }^{2}$ Apa makna kehadiran ketika kita semua tidak berada dalam ruang fisik yang sama, yaitu gereja? ${ }^{3}$ Apakah keikutsertaan kita dalam ibadah daring sudah mengindikasikan bahwa kita hadir dalam ibadah tersebut? ${ }^{4}$

Pertanyaan yang hendak diselidiki dalam penelitian ini adalah apa sebenarnya yang dimaksud dengan kehadiran. Kehadiran yang akan diselidiki bukan hanya bicara mengenai bukti dan tanda kehadiran, namun juga mengenai makna kehadiran. Apakah kita bisa memberi petunjuk mengenai kehadiran yang bermakna dalam ruang digital? Penjelasan definisi mengenai kehadiran menjadi penting karena dalam dunia yang memiliki berbagai cara untuk komunikasi, kita memiliki beberapa pemahaman yang berbeda mengenai istilah yang sama.

Artikel ini akan menganalisis makna kehadiran dalam penelusuran filosofi metaphysics of presence dari Martin Heidegger dan Jacques Derrrida. Dengan menggunakan pemikiran kedua filsuf fenomenologi, disimpulkan bahwa kehadiran dalam ruang digital yang memampukan subjek untuk berelasi dalam keterkaitan akan menghasilkan kehadiran yang bermakna.

${ }^{1}$ Penulis memahami digital sebagai ketersediaan dan penggunaan alat-alat untuk berkomunikasi melalui internet, baik dalam bentuk alat-alat pintar, digital, dan teknologi lainnya. Beberapa mungkin memahaminya juga sebagai virtual. Namun, karena keterbatasan bahasa dan pemaknaan kata "virtual" dalam Bahasa Indonesia yang akan ditampilkan di bawah, artikel ini akan tetap menggunakan kata digital dengan pemahaman di atas. Sementara itu arti digital menurut $K B B I$ online adalah "berhubungan dengan angka-angka untuk sistem perhitungan tertentu; berhubungan dengan penomoran."

2 Beberapa diskusi terkini bisa ditemukan dalam karya Erik Champion, ed., The Phenomenology of Real and Virtual Places (Abingdon, Oxon: Routledge, 2019); Bernd Blobaum, ed., Trust and Communication in a Digitized World. Models and Concepts of Trust Research (London; New York: Springer, 2016).

3 Diskusi mengenai peribadahan dalam ruang virtual sudah dibahas dalam karya Emmanuel B. Olusola, "Digital Church and E-Culture in the New Media Age: The Spectrum of Nigeria," African Ecclesial Review 57, no. 3 \& 4 (2015): 206-24; Teresa Berger, "Participatio Actuosa in Cyberspace? Vatican II's Liturgical Vision in a Digital World," Worship 87 (2013): 533-47; Erling Hope, "Between God and Google: Reflections on the Technology Project of the Society for the Arts, Religion and Contemporary Culture," CrossCurrents 62, no. 2 (2012): 235-59, https://doi.org/10.1111/j.1939-3881.2012.00232.x; Ryan Panzer, “Overcoming Digital Division: Digital Sacramentality as a Source of Healing," Journal of Religious Leadership 19, no. 1 (2020): 49-69.

${ }^{4}$ Lihat berbagai diskusi yang sudah ada mengenai kehadiran peribadahan di ruang digital, dalam Daniella Zsupan-Jerome, "Virtual Presence as Real Presence? Sacramental Theology and Digital Culture in Dialogue," Worship 89, no. 6 (2015): 526-42. 


\section{Metode Penelitian}

Artikel ini menggunakan analisis filsafat fenomenologi dalam metaphysics of presence Martin Heidegger dan kritik terhadap metaphysics of presence dari Jacques Derrida. Di akhir artikel, pemikiran mereka akan dibandingkan dan digunakan untuk mengonstruksi sebuah imajinasi jawaban mereka mengenai apa itu kehadiran dan bagaimana subjek bisa mengenali kehadiran subjek lainnya dalam ruang digital.

\section{Hasil dan Pembahasan}

\section{Definisi Kehadiran}

Dalam $K B B I$, hadir berarti "ada", sementara kehadiran berarti "adanya (seseorang, atau sekumpulan orang) pada suatu tempat." ${ }^{5}$ Dalam Oxford Dictionary, di bahasa Inggris, presence berarti "the fact of being in a particular place." Lawan kata dari hadir adalah absen. Absen berarti tidak masuk, dan tidak hadir. Kembali kita melihat bahwa pada arti pertama, absen berarti tidak ada-dalam definisi di atas-pada suatu tempat. Sementara itu dalam bahasa Inggris, absence berarti "the fact that somebody being away from a place where they are usually expected to be; the occasion or period of time when somebody is away."

Dalam bahasa Indonesia dan bahasa Inggris, baik kata hadir maupun absen terikat kepada ruang/tempat. Kalimat "berada pada sebuah tempat" tidak memberi definisi yang cukup jelas mengenai apa tempat yang dimaksud, apakah dia sebuah ruang tiga dimensi, atau ruang digital, atau bahkan apakah seseorang perlu ada secara tiga dimensi dalam ruang digital, atau ruang tiga fisik.

Untuk dapat melanjutkan diskusi ini, kita juga harus memberi definisi kepada apa yang dimaksud dengan ruang dan apa yang dimaksud dengan ruang tiga dimensi serta ruang digital. Dalam beberapa definisi tempat dan ruang di $K B B I$, ditemukan bahwa kata "tempat" selalu merujuk kepada sesuatu yang memiliki bentuk tiga dimensi: "wadah; bidang, rumah, daerah, negara, kota, desa," yang bisa digunakan untuk "menyimpan, melakukan sesuatu, mengumpulkan, didiami (ditinggali) atau ditempati."7

KBBI menggunakan kata virtual untuk definisi digital. Definisi virtual dalam KBBI justru lebih bermasalah, yaitu, " $a$ (secara) nyata; $a$ mirip atau sangat mirip dengan sesuatu yang dijelaskan; $a$ tampil atau hadir dengan menggunakan perangkat lunak komputer, misalnya di internet." 8 Kita tidak menemukan dengan jelas apa yang dimaksud dengan virtual. Sepertinya UU RI No. 11 tahun 2008 tentang Informasi dan Transaksi Elektronik lebih memberikan gambaran mengenai apa itu ruang virtual. Penjelasan Bagian I Umum, paragraf kedua menyatakan,

\footnotetext{
${ }^{5}$ KBBI Online, "hadir".

6 Oxford Dictionary Online, "presence".

${ }^{7} \mathrm{KBBI}$ Online, "tempat".

${ }^{8}$ KBBI Online, "virtual".
} 
"Istilah lain yang juga digunakan adalah hukum teknologi informasi (law of information technology), hukum dunia maya (virtual world law), dan hukum mayantara. Istilah-istilah tersebut lahir mengingat kegiatan yang dilakukan melalui jaringan sistem komputer dan sistem komunikasi baik dalam lingkup lokal maupun global (Internet) dengan memanfaatkan teknologi informasi berbasis sistem komputer yang merupakan sistem elektronik yang dapat dilihat secara virtual." 9

Dalam bahasa UU RI No. 11 tahun 2018 tentang ITE, "virtual” disamakan dengan "maya," yang justru menjadi membawa kepada masalah lain. "Maya” dalam KBBI berarti, "hanya tampaknya ada, tetapi nyatanya tidak ada; hanya ada dalam angan-angan; khayalan; merujuk pada fitur atau peranti yang tidak benar-benar ada, disimulasikan oleh komputer dan dapat digunakan oleh pengguna seolah-olah memang ada." Maya berarti sesuatu yang terlihat ada padahal tidak ada. Jika menggunakan pemahaman ini kepada kehadiran "virtual" vis-à-vis "maya," kita akan menghadapi masalah yang lebih besar lagi. Kehadiran di dunia maya adalah kehadiran khayalan, atau simulasi yang membuat sesuatu yang tidak ada seolah-olah memang ada. Penulis merasa penjelasan ini akan membawa kepada kesulitan yang baru dalam mendefinisikan kehadiran virtual. Perlu dicatat, kata "maya" sudah dihapus dalam UU No. 19 Tahun 2016 tentang Perubahan atas Undang-Undang Nomor 11 Tahun 2008.

Dalam bahasa Hukum, ruang virtual lebih memiliki kepastian yang tidak ada dalam pemahaman "maya" di atas. UU ITE No. 11 Tahun 2008, Bab 1 Pasal 1 poin 20 menyatakan bahwa,

"Nama Domain adalah alamat internet penyelenggara negara, Orang, Badan Usaha, dan/atau masyarakat, yang dapat digunakan dalam berkomunikasi melalui internet, yang berupa kode atau susunan karakter yang bersifat unik untuk menunjukkan lokasi tertentu dalam internet."10

Lokasi dalam internet atau nama domain bisa dimiliki dengan registrasi yang berarti ruang-ruang tersebut bukan tak bertuan. Kemudian, ada juga kode unik Internet Protocol Address (IP Address) yang bisa menunjukkan lokasi tertentu berdasarkan penyedia jaringan yang kita gunakan. Penyedia jaringan mencatatkan tiap IP addressnya melalui berbagai regulasi. Lokasi dalam internet dalam nama domain dan cara kita mengaksesnya melalui penyedia jaringan internet memperlihatkan koneksi yang tidak "maya" dalam pemahaman di KBBI, melainkan bisa ditelusuri melalui adanya berbagai aturan. Dalam bagian penjelasan bagian umum Paragraf 7, ditambahkan klausul seperti ini,

"Kegiatan melalui media sistem elektronik, yang disebut juga ruang siber (cyber space), meskipun bersifat virtual dapat dikategorikan sebagai tindakan atau perbuatan hukum yang nyata... Kegiatan dalam ruang siber adalah kegiatan virtual yang berdampak sangat nyata meskipun alat buktinya bersifat elektronik." 11

${ }^{9}$ UU RI No. 11 tahun 2008 tentang Informasi dan Transaksi Elektronik, Penjelasan Bagian I Umum, paragraf 2.

${ }^{10}$ UU RI No. 11 Tahun 2008 tentang ITE, Bab 1 Pasal 1 poin 20

11 UU RI No. 11 tahun 2008 tentang Informasi dan Transaksi Elektronik, Penjelasan Bagian I Umum, paragraf 7. 
Kegiatan dalam ruang virtual ternyata dianggap resmi berdampak nyata, yang kita artikan dengan bukti kegiatan virtual bisa digunakan sebagai alat untuk menyatakan kehadiran. Undang-Undang RI No. 19 Tahun 2016 tentang Perubahan atas UndangUndang Nomor 11 Tahun 2008 tentang Informasi dan Transaksi Elektronik memperkuat keabsahan berbagai peristiwa yang terjadi di ruang virtual yang memengaruhi ruang tiga dimensi. Bagian penjelasan Bab I Umum mencantumkan pemahaman ini,

Ketiga, karakteristik virtualitas ruang siber memungkinkan konten ilegal seperti Informasi dan/atau Dokumen Elektronik yang memiliki muatan yang melanggar kesusilaan, perjudian, penghinaan atau pencemaran nama baik, pemerasan dan/atau pengancaman, penyebaran berita bohong dan menyesatkan sehingga mengakibatkan kerugian konsumen dalam Transaksi Elektronik, serta perbuatan menyebarkan kebencian atau permusuhan berdasarkan suku, agama, ras, dan golongan, dan pengiriman ancaman kekerasan atau menakut-nakuti yang ditujukan secara pribadi dapat diakses, didistribusikan, ditransmisikan, disalin, disimpan untuk didiseminasi kembali dari mana saja dan kapan saja. ${ }^{12}$

Dari bahasa hukum, disimpulkan bahwa ruang virtual adalah "suatu lokasi tertentu di Internet yang terikat dalam nama domain yang digunakan untuk berkomunikasi, yang kegiatan di dalamnya berdampak sangat nyata bagi ruang tiga dimensi." Ruang "virtual" dalam definisi ini kemudian dinamai ruang digital. Pemahaman "digital" dalam KBBI juga tidak tepat, yaitu "berhubungan dengan angkaangka untuk sistem perhitungan tertentu; berhubungan dengan penomoran." 13 Kita akan menggunakan pemahaman digital seperti pemahaman Oxford Dictionary yang lebih mengarah kepada cara sistem yang menggunakan informasi yang diterjemahkan dalam angka, yaitu "using a system of receiving and sending information as a series of the numbers one and zero, showing that an electronic signal is there or is not there." Digital berarti sistem yang menggunakan angka satu dan nol dengan sinyal elektronik. Kehadiran dalam ruang digital berarti kehadiran yang direpresentasikan melalui sinyal elektronik satu dan nol yang mentransmisikan bukti kehadiran dalam bentuk teks/gambar, suara, dan video.

Jika kehadiran berarti "adanya (seseorang, atau sekumpulan orang) pada suatu tempat" dan tempat berfungsi menjadi "wadah atau tempat" untuk "menyimpan atau melakukan sesuatu," tempat digital dan kehadiran di tempat digital tersebut secara hukum bisa diartikan sebagai kehadiran.

Meski demikian, kehadiran dalam ruang digital memiliki tantangannya tersendiri ketika berbicara mengenai makna kehadiran dalam pemahaman filosofis, terutama dalam kehidupan peribadahan. Apakah kehadiran akun digital seseorang pada ibadah di ruang digital menyatakan kehadirannya? Apa tanda dan bukti kehadiran?

12 UU RI No. 19 Tahun 2016 tentang Perubahan atas Undang-Undang Nomor 11 Tahun 2008 tentang Informasi dan Transaksi Elektronik, Bagian Penjelasan Bab I Umum, paragraf 9.

13 KBBI Online, "digital”. 


\section{Kehadiran dalam Filsafat Heidegger dan Derrida}

Pertanyaan utama dalam memahami kehadiran bisa disimpulkan dalam pertanyaan yang diajukan oleh Heidegger, mengapa sesuatu ada daripada tidak ada. Dengan kata lain, bagaimana kita memberi definisi bahwa sesuatu itu ada atau hadir. Segera setelah kita memberi pertanyaan ini, berbagai turunan diskusi muncul.

Siapa yang memutuskan bahwa sesuatu hadir, apakah sang objek atau subjek yang kepadanya yang hadir ini menyatakan diri? Dalam ruang digital misalnya, siapakah yang berhak menyatakan kehadiran? Ketika dalam subjek mengamati kehadiran, bolehkah subjek memberi penilaian kehadiran atau apakah objek boleh menyatakan dirinya sendiri hadir tanpa persetujuan subjek? Penelitian ini akan mencoba mengusulkan pemahaman kehadiran sebagai sesuatu yang definitif, yaitu kehadiran yang membuatnya tidak subjektif.

Bagaimana cara sang objek mengungkapkan dirinya kepada subjek? Pertanyaan mempertanyakan bagaimana kehadiran kemudian berhubungan juga dengan aksi atau event. Kehadiran harus didukung dengan adanya sebuah aksi yang membuat subjek mengenali objek sebagai ada. Apakah kehadiran harus dipahami secara resiprokal ketika subjek dan objek manusia, atau, apakah hanya subjek yang mengenai kehadiran objek, atau bisakah objek mengenali kehadiran subjek, atau apakah keduanya menjadi subjek dan objek pada saat yang bersamaan? Dalam pertanyaan ini, kita menemukan sebuah pertanyaan mengenai relasi subjek dan objek. Apakah ketika kedua pihak menjadi objek dan subjek pada saat yang sama, pemahaman mengenai kehadiran dalam relasi menjadi bergantung satu dengan yang lain?

Apa yang kita sebut dengan saat bersamaan? Dalam kehadiran kita memahami juga aspek temporalitas, keterikatan kepada horizon waktu. Kehadiran dalam bahasa Inggris presence dekat artinya dengan present. Kehadiran menunjukkan keberadaan dalam sebuah masa yang berarti dimulai dan kemungkinan berakhir pada sebuah waktu.

Pada akhirnya, apa identitas yang dikenakan kepada objek atau yang identitas yang diperkenalkan objek kepada subjek? Apa signifikansi identitas objek yang membuatnya distingtif terhadap subjek? Tritten mengenali pentingnya identitas dalam diskursus mengenai presence, bahwa,

Yet, perhaps one identifying characteristic all critiques of presence possess is that they attempt to move beyond identity... the recognition of something as something or other in order that that category and that unification of particulars may be iden-tified (I.D.ed) as having that specific identity. ${ }^{14}$

Ketika subjek mengenal kehadiran objek, ada identitas yang membuatnya mengenali objek. Identitas objek adalah kesamaan yang dimiliki oleh subjek karena subjek harus mengenali identitas objek untuk bisa menyatakan kehadiran.

14 Tyler Tritten, Beyond Presence: The Late F. W. J. Schelling's Criticism of Metaphysics (Boston; Berlin: De Gruyter, 2012), 9. 
Dalam hal kehadiran di ruang digital, berbagai pertanyaan di atas bisa kita terapkan untuk mencari tahu apa kehadiran dari perspektif mengapa dan untuk apa ada kehadiran, dan pada akhirnya akan menjawab apakah kehadiran di ruang digital adalah kehadiran. Kita akan mencoba mengurai berbagai pertanyaan di atas dengan bantuan pemikiran Martin Heidegger dalam Being and Time serta teori deconstruction dan diffarence Jacques Derrida. Melalui teori Heidegger, kita akan menemukan bahwa pencarian makna akan kehadiran membuat kita menjadi makhluk yang mencari tahu, bergerak memaknai peristiwa yang terjadi setelah memahami kehadiran kita di dunia, dan pada akhirnya menjadi bukti kehadiran. Sementara itu, Derrida akan mengingatkan kita untuk berhati-hati dalam memberi definisi yang akhirnya bisa menegasikan kehadiran yang lain karena tidak sesuai dalam kerangka berpikir sang subjek. Melalui pemikiran Derrida, kita akan menemukan faktor "saling" dan "keterkaitan" antarsubjek sehingga kehadiran bukan lagi hal yang subjektif melainkan objektif di antara mereka yang hadir. Meski Heidegger dan Derrida berlawanan dalam pengembangan pemahaman mereka atas fenomenologi, bahkan keduanya juga tidak bicara mengenai kehadiran di ruang digital, pemahaman mereka mengenai kehadiran dan pemaknaan kehadiran akan membantu kita memberi definisi mengenai apa yang sekarang kita hadapi dalam ruang digital. Penelitian ini akan memaparkan inti pemikiran keduanya mengenai kehadiran, dan kemudian mengadakan sebuah percakapan imajinatif antara kedua filosof mengenai ruang digital.

\section{Metaphysics of Presence Martin Heidegger}

Secara filosofis, pertanyaan mengenai kehadiran menjadi poin penting dalam peneluran filosofi Martin Heidegger dalam mahakaryanya Being and Time. ${ }^{15}$ Heidegger mempunyai hubungan pertemanan dengan Edmund Husserl yang kemudian memengaruhinya untuk memasuki diskursus fenomenologi. Heidegger sempat mengajar di Marburg dan di situ dia menulis mahakaryanya Sein und Zeit (Being and Time) (1927), yang ditulisnya untuk Husserl.

Analisis keberadaan atau presence dimulai ketika Heidegger harus menjelaskan makna vorhandenheit yang diterjemahkan menjadi presence-at-hand. Vorhandenheit adalah objek yang datang kepada saya sang subjek. Filsafat selalu berusaha untuk memahami objek dan Heidegger memahaminya dengan bantuan horizon waktu. Dalam Being and Time, Heidegger mencoba memahami ontologi keberadaan. Apa itu keberadaan dan mengapa sesuatu ada daripada tidak ada. Being ${ }^{16}$ secara sederhana

15 Martin Heidegger, Being and Time, trans. John Macquarrie and Edward Robinson (Oxford: Basil Blackwell, 1962).

16 Penulis menerjemahkan Being (Jerman: Sein) sebagai keberadaan atau ada. Untuk menjaga bentuk terjemahan Bahasa Inggris yang penulis gunakan, semua kata Being merupakan kata asli dari versi terjemahan yang penulis gunakan. 
selalu dipahami secara ontologis, yaitu dari kehadirannya, dari Being yang hadir. ${ }^{17}$ Dengan ontologi, Being dipahami hanya sebagai suatu generalisasi yang memberinya sebuah atribut. Pemahaman kehadiran sedemikian hanya membuat pertanyaan mengenai ide dan materi (mind and matter; dalam dunia ide atau empiris), representasi kehadiran, kesadaran yang melihat kehadiran, dan pembedaan antara atribut kehadiran dan mereka yang mewakilinya.

Heidegger menolak pemahaman para filsuf Barat sebelumnya yang membuat kita memahami ontologi sebagai hal-hal yang ada dan yang berhubungan dengan kehadirannya. ${ }^{18}$ Ontologi menjadi diskusi mengenai apa dampak dari kehadiran Being tanpa pernah membicarakan mengapa mereka mengada dan bukan tidak ada. Argumen mengenai alasan religius yang ada di balik maksud keberadaan adalah onto-teologi dan tidak bisa dibenarkan. ${ }^{19}$

Heidegger berargumen bahwa ada tiga alasan mengapa makna kehadiran being tidak dipertanyakan, yaitu: Being itu adalah konsep universal, dia tidak bisa didefinisikan, dan makna Being seolah-olah sudah hadir pada dirinya sendiri. ${ }^{20}$ Ketiga hal ini membuat kita lupa bertanya mengenai makna Being dan hanya menilai kehadirannya. Untuk bertanya mengenai makna Being bukanlah hal yang mudah. Heidegger memfomulasikan struktur pertanyaan mengenai Being, yaitu,

Any inquiry, as an inquiry ahout something, has that which is asked about [sein Gefragtes]. But all inquiry about something is somehow a questioning of something [Anfragen bei ... ]. So in addition to what is asked about, an inquiry has that which is interrogated [ein Befragtes]. In investigative questions-that is, in questions which are specifically theoreticalwhat is asked about is determined and conceptualized. Further-more, in what is asked about there lies also that which is to be found out by the asking [das Erfragte]; this is what is really intended: with this the inquiry reaches its goal.21

Tiga hal di atas, das Gefragtes, das Befragtes, dan das Erfragte sulit untuk diterjemahkan ke dalam bahasa Indonesia. Kita bisa memahami pertanyaan mengenai Being sebagai pencarian makna dalam keterikatannya terhadap bentuk waktu. Harman memberi penjelasan untuk memahami pernyataan Heidegger di atas. Setiap pertanyaan terhadap Being menganalisis tiga hal: pertama, apa yang telah ditanyakan (that which is interrogated [ein Befragtes]), kedua, untuk memahami apa yang baru (that which is to be found out by the asking [das Erfragte]), dan ketiga, dengan hasil jawaban kedua

17 Heidegger, Being and Time, 22-23.

18 Heidegger, 31. Dia menuliskan, "Basically, all ontology, no matter how rich and firmly compacted a system of categories it has at its disposal, remains blind and perverted from its ownmost aim, if it has not first adequately clarified the meaning of Being, and conceived this clarification as its fundamental task."

19 Pendapat ini sendiri ditolak oleh beberapa penulis terkini, misalnya Tritten yang menggunakan pemikiran Friedrich Wilhelm Joseph Von Schelling untuk menyatakan bahwa pencarian yang disebut Heidegger sebagai onto-theology justru dibutuhkan untuk tidak jatuh ke dalam kenihilan. Namun demikian, kita tidak akan membahas pemikiran Schelling atau Tritten lebih lanjut karena kita akan menggunakan pemikiran Heidegger untuk hal yang berbeda. Tritten, Beyond Presence, 347.

${ }^{20}$ Heidegger, 22-23.

${ }^{21}$ Heidegger, 24. 
pertanyaan terdahulu memberi kita pertanyaan yang menyeluruh (that which is asked about [sein Gefragtes]). ${ }^{22}$ Dengan kata lain, Being harus lebih dulu mempertanyakan dirinya untuk menyadari keberadaannya. Being adalah subjek yang dituntut untuk mempertanyakan diri sendiri. Di sini Heidegger membedakan pencarian ontologis yang menurutnya lebih menanyakan natur dari yang ada (Being) dengan pencarian ontical yaitu pencarian tentang realitas konkret dan yang ada (entities) dan fakta mengenai keberadaan mereka. Buat Heidegger, ontical berarti keberadaan yang konkret dan spesifik seperti kesadaran diri, apa yang mungkin terjadi di masa depan, dan juga jejaring dari relasi dengan yang lain. ${ }^{23}$

Dengan demikian, Heidegger memperkenalkan konsep Dasein sebagai Being yang menyadari keberadaannya dalam dunia (being-in-a-world). Being yang menyadari dan mempertanyakan kehadirannya menjadi Dasein ketika dia ada dalam dunia. Manusia menjadi Dasein karena manusia mampu mempertanyakan keberadaannya. Kehadiran tidak boleh dibiarkan terjadi begitu saja, karena pencarian makna justru harus dilakukan oleh Dasein itu sendiri. Dalam pencarian makna Dasein selalu berada dalam relasi dengan yang lain. Yang menjadikan Dasein berbeda dengan yang lain adalah bahwa dia mempertanyakan mengapa dia ada dan dia menyadari bahwa kehadirannya adalah esensinya. Untuk dapat mengetahui makna keberadaannya, Dasein harus memahami konsep waktu dalam sejarah. ${ }^{24}$

Dasein hadir dalam sejarah dan temporalitas waktu. Kesadaran dasein akan ruang ada dalam pemahamannya mengenai kehadiran dalam ruang, yang dia juga sebutkan sebagai dunia. Kehadiran jenis pertama adalah Anwesenheit yaitu kehadiran di masa ini dan sekarang. ${ }^{25}$ Kehadiran jenis ini berarti kehadiran dalam sebuah ruang dan waktu dan terlibat dalam sebuah aktivitas. Heidegger memahami bahwa kehadiran bentuk ini adalah sementara. Dasein bukan hanya anwesen atau hadir, dia juga berusaha menjawab pertanyaan mengenai keberadaannya keterlibatannya dalam event di kehidupannya. Ketika dia melakukan berbagai aktivitas, Dasein akan berusaha untuk memahami apa yang dilakukannya dan mengapa dia melakukan itu. Aktivitas yang

22 Graham Harman, Heidegger Explained: From Phenomenon to Thing (Chicago; La Salle, IL: Open Court, 2007), 57. Bandingkan dengan penjelasan Michael Watts, Heidegger: A Beginner's Guide (Abingdon, Oxon: Hodder \& Stoughton, 2001), 11-23.

23 Ada kesulitan untuk menerjemahkan kata ontical karena penjelasan yang cukup singkat diberikan oleh Heidegger dalam catatan kaki 3 dalam Heidegger, 31, namun dalam penjelasan selanjutnya kita bisa memaknai bahwa ontical berbeda dengan ontologi karena ontical lebih bicara mengenai sesuatu yang spesifik ada.

${ }^{24}$ Heidegger, 32, 34-35.

25 Heidegger, 47. Heidegger menuliskan bahwa dalam memahami temporalitas waktu, pemahaman Being hanya bisa dimiliki ketika dia berada dalam waktu itu sendiri. Lebih lanjut, "The

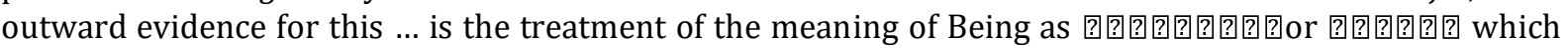
sigfnifies, in ontologico-Temporal terms, 'presence' ["Anwesenheit”]. Lihat penjelasan Michael Inwood, The Blackwell Philosopher Dictionaries: A Heidegger Dictionary (Malden, MA: Blackwell Publishers Ltd., 1999), 174-175. Anwesenheit adalah kesadaran Being akan kehadirannya. 
dilakukannya bukan sesuatu yang spesial, namun pemaknaan mengenai kehadiran justru dilakukan Dasein dalam kegiatan kesehariannya, atau yang disebutnya sebagai "average everydaynesss."26 Dasein harus mampu mencari pemaknaan kegiatannya dari sekadar mengikutinya. Heidegger menamakan kebutuhan pemaknaan ini sebagai presence-at-hand (Jerm.: Vorhandenheit atau Vorhandensein). Dalam pemahaman literer, vorhanden berarti di depan tangan dan Heidegger menggunakan istilah ini untuk merujuk kepada materi yang bukan Dasein. Vorhanden adalah materi yang terbatas kepada ruang dan waktu.

Watts menggambarkan pemahaman Dasein bahwa subjek harus selalu meneliti dan berefleksi mengenai dirinya sementara dia hadir dalam kegiatan setiap hari atau dunia atau sebuah ruang (being-in-the-world), dan dia selalu merasakan kehadiran dalam relasi dengan yang lain. ${ }^{27}$ Bagi Heidegger, kehadiran subjek berkenaan dengan relasi spasial (Being-in atau Being di dalam) dan berkenaan dengan yang lain (Being-inthe-world atau Being yang bersama being yang lain dalam dunia). ${ }^{28}$ Dalam relasi spasial, Heidegger menyatakan, "Being-in" adalah "the formal existential expression for the Being of Dasein which has Being-in-the-world as its essential state."29 Artinya, ketika Being terlempar (istilah Heidegger thrownness) ke dalam dunia dan menjadi hadir dalam dunia. Kehadiran terbatas kepada proses menjadi dalam dirinya sendiri dan waktu yang membatasi Dasein adalah apa dirinya sendiri. ${ }^{30}$ Sementara itu, ruang bagi Heidegger bukanlah seperti pemahaman ruang yang kita kenal, terbatas pada bentuk tiga dimensi, atau digital seperti yang kita definisikan di atas. Ruang menjadi sebuah tempat di mana relasi antara bisa terjadi dan di mana Dasein menyadari keberadaannya di ruang itu. ${ }^{31}$ Heidegger menyatakan istilah Befindlichkeit (findingness atau Fried menerjemahkannya sebagai enrooted attunement) digunakan untuk menggambarkan kesadaran Being yang ternyata menemukan dirinya berada dalam sebuah situasi di mana kata-kata bisa memengaruhi kesadaran di dalamnya dalam cara tertentu. ${ }^{32}$ Befindlichkeit juga

${ }^{26}$ Heidegger, 38.

${ }^{27}$ Heidegger menjelaskan, "Of course Being-in-the-world is a state of Dasein which is necessary $a$ priori, but it is far from sufficient for completely determining Dasein's Being." Heidegger, 79.

28 Watts, Heidegger: A Beginner's Guide, 32.

${ }^{29}$ Heidegger, 80.

30 Dieter Thomä, “The Imperative Mode of Heidegger's Thought, National Socialism, and AntiSemitism," dalam Confronting Heidegger: A Critical Dialogue on Politics and Philosophy, New Heidegger Research, Gregory Fried, peny. (London; New York: Rowman \& Littlefield, 2020), 154.

31 Harman, Heidegger Explained: From Phenomenon to Thing, 35, bandingkan dengan Jussi Backman, Complicated Presence: Heidegger and the Postmetaphysical Unity of Being, SUNY Series in Contemporary Continental Philosophy (Albany, NY: Suny Press, 2015), 103. Heidegger menyatakan istilah Befindlichkeit (findingness atau Fried menerjemahkannya sebagai enrooted attunement) untuk menggambarkan kesadaran Being yang ternyata menemukan dirinya berada dalam sebuah situasi di mana kata-kata bisa memengaruhi kesadaran di dalamnya dalam cara tertentu.

32 Fried, Confronting Heidegger: A Critical Dialogue on Politics and Philosophy, 186. Sementara itu, Hart menerjemahkan Befindlichkeit sebagai "state of mind" or, with less of an analytical flavor, "already having found-itself there-ness." Kevin Hart, "Introduction" dalam The Experience of the Kingdom of God, ed. Kevin Hart and Barbara E. Wall, Perspectives in Continental Philosophy (New York: Fordham University Press, 2005), 14. 
diterjemahkan sebagai mood atau perasaan Dasein dalam kesadarannya membuatnya bukan menjadi Vorhandenheit. Hanya melalui mood atau attunement, Dasein menyadari keterlemparannya di dunia dan membuatnya memberikan respons. Dunia, atau ruang adalah tempat relasi menjadi mungkin. Ketika Being mampu berelasi di ruang di mana dia terlempar, ruang itu menjadi ruang yang sesungguhnya.

Inti dari pemikiran Heidegger yang digunakan dalam makalah ini adalah pemahaman keterlemparan Dasein ke dunia, dan bagaimana Dasein memahami dunia atau ruang sebagai tempat yang memungkinnya berelasi dengan yang lain. Heidegger tidak bicara mengenai ruang digital, sehingga di sini kita akan menggunakan konstruksi imajinatif mengenai keterlemparan subjek di ruang digital. Heidegger mendefinisikan ruang sebagai tempat di mana subjek berelasi dengan yang lain, dengan demikian, ruang digital juga bisa kita definisikan sebagai ruang dalam pemahaman Heidegger. Seseorang yang memasuki ruang digital harus menyadari "keterlemparannya" dalam ruang itu dalam pengetahuan dan kesadaran mencari makna, dan memberi respons atasnya. Keterlemparannya dalam ruang itu akan membuatnya menjadi subjek yang menyadari kehadiran subjek lain. Dalam kesadaran akan kehadiran subjek lain, subjek-subjek akan memiliki relasi antarsubjek. Relasi dalam ruang digital juga menjadi relasi yang "saling" di antara peserta sehingga para subjek menyadari dan merefleksikan kehadirannya.

Yang belum terjawab adalah bagaimana relasi antar-Dasein bisa terjadi dalam ruang dan bagaimana mereka memahami bahwa mereka yang hadir dalam ruang tersebut adalah Dasein dan bukan sekadar Being? Lebih lanjut, penelusuran akan pemikiran Heidegger mengenai dengan cara hadir, atau dalam bahasa Heidegger, cara subjek terlempar dalam ruang digital, belum terjawab. Bagaimana Dasein menunjukkan kesadarannya kepada Dasein lainnya sehingga semua menyadari keterlibatannya dalam ruang digital? Pertanyaan ini akan kita coba jawab dengan pemahaman Jacques Derrida dengan prinsip presence dan absence dalam penanda dan jejak.

\section{Kritik terhadap Metaphysics of Presence dari Jacques Derrida}

Satu teori yang bisa membantu kita untuk memahami makna kehadiran dalam ruang adalah kritik Derrida mengenai metafisika kehadiran atau "metaphysics of presence." Jacques Derrida (1930-2004) mempelajari fenomenologi Husserl di Husserl Archive di Leuven, Belgia. Derrida menerbitkan karya Of Grammatology 33 yang menjadi materi kita untuk memahami kehadiran. Dalam menelusuri argumen Derrida mengenai kehadiran (presence) kita juga harus melihat konsep ketidakhadiran (absence), mimesis dan representasi.

33 Jacques Derrida, Of Grammatology, trans. Gayatri Chakravorty Spivak, Corrected (Baltimore, Maryland: The Johns Hopkins University Press, 1976). 
Derrida memulai karyanya dengan Husserl yang menjadi bapa fenomenologi dan masuk kepada pemikiran Heidegger. Dalam fenomenologi Husserl, pertanyaan utama yang diajukan adalah bagaimana kita bisa mengenali objek sebagaimana objek ingin bercerita kepada kita. Derrida mengenali bahwa dunia filsafat Barat telah banyak bersandar kepada speech (ucapan) dibandingkan writing (tulisan) sebagai penanda kehadiran. Logosentris percaya akan adanya kebenaran dan asal atau penyebab absolut dari segala sesuatu. Dalam karyanya Of Grammatology, Derrida mengritik karya ahli bahasa asal Swiss Ferdinand de Saussure Course in General Linguistics, yang lebih mengutamakan ucapan daripada tulisan.

Derrida tidak setuju dengan anggapan bahwa ucapan adalah kebenaran yang paling dasar dari penyampaian makna karena ucapan juga dipengaruhi oleh bahasa. ${ }^{34}$ Dalam memulai karyanya, Derrida menyatakan, “...this exergue must not only announce that the science of writing-grammatology-shows signs of liberation all over the world, as a result of decisive efforts." 35 Dari pemahaman bahwa teks dalam tulisan adalah bentuk penyampaian kehadiran yang utama, Derrida menyatakan, "There is nothing outside of the text [there is no outside-text; il n'y a pas de hors-texte]."36 Teks menjadi penanda dari kehadiran. Sebagai penanda kehadiran, teks menjadi "a fabric of traces referring endlessly to something other than itself, to other differential traces." 37 Dalam menjelaskan teks, Derrida juga keberatan batasan atau ujung untuk pemahaman teks. Untuk menjelaskan teks sebagai narrasi, ketika teks adalah récit (cerita, narasi), adalah mencari konteks dari narasi tersebut, atau dalam bahasa Derrida,

To know (before we know) what narrative is, the narrativity of narrative, we should perhaps first recount, return to the scene of one origin of narrative, to the narrative of one origin of narrative (will that still be a narrative?), to that scene that mobilizes various forces, or if you prefer various agencies or "subjects," some of which demand the narrative of the other, seek to extort it from him, like a secret-less secret, something that they call the truth about what has taken place: "Tell us exactly what happened."38

Pada momen ini pemahaman teks beralih dari tulisan yang terbatas pada buku menjadi teks sebagai konteks narasi. Dalam sebuah wawancara, Derrida mengatakan bahwa apa yang disebutnya teks adalah "implies all the structures called "real," "economic," "historical," socio-institutional, in short: all possible referents."39 Derrida memberi perumusan baru pemahaman teks sebagai,

The phrase which for some has become a sort of slogan, in general so badly understood, of deconstruction ("there is nothing outside the text" [it n y a pas de hors-texte]), means nothing else: there is nothing outside context. ${ }^{40}$

${ }^{34}$ Derrida, Of Grammatology, 3-4.

35 Derrida, Of Grammatology, 4.

${ }^{36}$ Derrida, Of Grammatology, 158.

37 Jacques Derrida, "Living On" trans. James Hulbert, in Deconstruction and Criticism, ed. Harold Bloom et al., (London; Henley: Routledge \& Kegan Paul, 1979), 84.

${ }^{38}$ Derrida, "Living On," 88.

${ }^{39}$ Jacques Derrida, Limited Inc., ed. Gerard Graff, trans. Samuel Weber and Jeffrey Mehlman (Evanston, IL: Northwestern University Press, 1988), 148.

${ }^{40}$ Derrida, Of Grammatology, 136. 
Pemaknaan tidak bisa dilepaskan dari konteks, yaitu ucapan, kehidupan, dunia, sejarah, dan berbagai konteks yang mewakili sebuah masa. Teks bukan hanya soal tulisan, melainkan segala struktur yang menjumpai kita secara riil. Konteks pada akhirnya merujuk kepada sebuah struktur yang menjadi penanda kehadiran yang melampaui kehadiran, dan saat ini akan disebut sebagai representasi kehadiran. Representasi kehadiran melalui penanda kehadiran bagi Derrida juga adalah kehadiran.

Mereka yang mengutamakan ucapan (speech) sebagai penanda utama, akan memiliki pemahaman bahwa ada ukuran kebenaran yang memastikan struktur keberadaan dan pengenalan akan keberadaan menjadi tetap ada. Penanda transenden (transcendental signified) dianggap menjadi kebenaran yang ada di pusat keberadaan, yang menjadi kebenaran yang melampaui segala struktur dunia. Kita mengenali ide akan yang utama ini dalam berbagai istilah, dunia ide, Roh, kesadaran, atau Yang Mutlak.

Derrida ingin mencoba keluar dari faktor pengalaman subjek dalam mengetahui fenomena yang datang kepadanya karena struktur pengalaman tidak bebas nilai dan selalu bias. ${ }^{41}$ Struktur adalah akibat dari kebutuhan untuk melakukan framing (Yunani: ergon - kerja; dan parergon - di luar kerja), yaitu pekerjaan untuk memaknai fenomena. Bagi Derrida, pekerjaan untuk mencoba memahami fenomena akan membuat kita memisahkan yang di dalam (ergon) karena kita sudah membuat batas yang di luar (parergon). Dia mengatakan,

No "theory," no "practice," no "theoretical practice" can intervene effectively in this field if it does not weigh up and bear on the frame, which is the decisive structure of what is at stake, at the invisible limit to (between) the interiority of meaning (put under shelter by the whole hermeneuticist, semioticist, phenomenologicalist, and formalist tradition) and (to) all the empiricisms of the extrinsic which, incapable of either seeing or reading, miss the question completely. ${ }^{42}$

Dalam bahasa dan gaya argumentatif Derrida mengenai lukisan dan bingkai, dia ingin mengatakan bahwa percobaan untuk memahami fenomena justru sering dibatasi oleh kotak/frame yang subjek miliki sebelum dia berhasil memaknai apa yang datang kepadanya. Dalam hal lukisan, seseorang justru memahami lukisan karena frame yang dia miliki, bukan apa yang dilihatnya.

Usaha untuk menginterpretasi fenomena harus dimulai dari dekonstruksi atau pemindahan dari pusat (decentering) dan pemahaman harus dimulai dari dekonstruksi logos. Logos bisa juga kita pahami sebagai kebenaran yang sudah dipegang selama ini. Kita harus menyingkirkan centre (pusat), karena pusat memberitahu kepada kita apa makna dari objek yang datang kepada kita. Pusat cenderung menekan dan menyingkirkan yang berbeda dengannya.

${ }^{41}$ Jacques Derrida, Writing and Difference, trans. Alan Bass (London; New York: Routledge, 1978), $4-7$.

42 Jacques Derrida, The Truth in Painting, trans. Geoff Bennington and Ian McLeod (Chicago; London: The University of Chicago Press, 1987), 61. 
Teori Derrida yang utama deconstruction sulit untuk diberi definisi karena setiap definisi yang adalah berarti memberinya sebuah bingkai, yang akhirnya menyalahi apa yang ingin dibawanya. Kita bisa memulai penjelasan mengenai deconstruction dengan penolakan akan otoritas yang berusaha memberi bingkai. Dalam sebuah surat, Derrida mengatakan, "it is an event that does not await the deliberation, consciousness, or organization of a subject, or even of modernity. It deconstructs it-self. It can be deconstructed [Ça se déconstruit]." 43 Karena itu kita tidak bisa menetapkan definisi teori deconstruction. Deconstruction mungkin lebih seperti teknik atau metode untuk mengenali apa yang datang (membaca teks). Deconstruction menggoyahkan pemahaman utama dan definisi yang sudah menjadi stabil. Sebelum kita bisa memberi deskripsi kita harus menyadari apa bingkai yang kita miliki dalam menggambarkan sesuatu yang datang kepada kita. Karena itu, ucapan juga tidak pernah lepas dari nilai yang dimiliki oleh mereka yang mendengarkannya. Kehadiran dalam bentuk ucapan perlu dimaknai ulang, terutama dalam bentuk selain ucapan.

Di sini kita harus memahami mengenai apa itu representasi kehadiran. Dalam pencariannya mengenai kehadiran, Derrida membahas penolakannya akan argumen Rousseau tentang imitasi atau mimesis sebagai representasi kebenaran. ${ }^{44}$ Bagi Derrida, dalam seni mimesis akan menduplikasi kehadiran sebagai yang menambah kehadiran atau melengkapinya (suplemen). Jika mimesis bukan penanda kehadiran, apa yang bisa kita gunakan sebagai penanda? ${ }^{45}$

Bagi Derrida, tanda (sign), sepertinya masih mengikuti pendapat umum dalam Filsafat Barat, berarti ekspresi yang bisa ditangkap oleh indra, sementara simbol adalah kegunaan yang bermakna dari ekspresi tersebut. Sebuah tanda bisa diwakili oleh simbol sementara simbol menjelaskan tanda. ${ }^{46}$ Sebuah tanda selalu memiliki dua faktor yaitu signifier (penjelas) dan signified (yang dijelaskan). Signified dan signifier memiliki hubungan yang membentuk kesatuan karena kita tidak bisa menjelaskan yang kita jelaskan tanpa hubungan tersebut. Relasi dari signified dan signifier dijelaskan oleh Derrida,

The formal essence of the signified is presence, and the privilege of its proximity to the logos as phone is the priviledge of presence. This is the inevitable response as soon as one asks:

43 Jacques Derrida, "Letter to a Japanese Friend”, dalam D. Wood and R. Bernasconi (eds), D. Wood and A. Benjamin (trans.), Derrida and Différance. Evanston, IL: Northwestern University Press, 274.

44 Derrida, Of Grammatology, 203-204. Menurut Cambridge Dictionary of Philosophy, Mimesis adalah "the modeling of one thing on another, or the pre- senting of one thing by another; imitation," dalam Robert Audi, ed., The Cambridge Dictionary of Philosophy, Second Edition (Cambridge: Cambridge University Press, 1995), 552.

45 Derrida, Of Grammatology, 11. Di bagian ini Derrida mengutip pertanyaan Aristoteles, bahwa "If, for Aristotle, for example, "spoken words ( $t a$ en te phone) are the symbols of mental experience (pathemata tes psyches) and written words are the symbols of spoken words" (De Interpretatione, 1, 16a 3 ) it is because the voice, producer of the first symbols, has a relationship of essential and immediate proximity with the mind. Producer of the first signifier, it is not just a simple signifier among others."

46 Nicholas Bunnin and Jiyuan Yu, The Blackwell Dictionary of Western Philosophy (Malden, MA; Oxford, UK: Blackwell Publishing Ltd., 2004), 640. 
"what is the sign?," that is to say, when one submits the sign to the question of essence, to

the "ti esti." The "formal essence" of the sign can only be determined in terms of presence. Kehadiran dari signified dijelaskan oleh signifier. Signified akan selalu hadir dalam masa lalu dan menimbulkan jarak antara kehadirannya dan kemampuan kita untuk menangkap signified tersebut. Pertemuan kita dengan signified selalu diselingi absence, yaitu jarak antara signified dan yang berusaha memaknainya. Karena itu sang signified yang ideal kita temukan dalam jejak (trace). Tulisan (text) dapat menjembatani keterpisahan signified dan signifier karena kehadirannya yang langsung ke kita. ${ }^{47}$ Tulisan bahkan bisa menjadi kehadiran yang diulangi setiap kali subjek muncul. Tulisan menjadi institusi penyampai makna yang bertahan melampaui waktu dan tanda bahasa.

Dari pemikiran Derrida, bentuk kehadiran tidak bisa dilepaskan dari signified dan signifier serta cara mereka hadir kepada subjek yang bertemu dengan teks. Teks adalah struktur nyata yang ditangkap oleh subjek, dengan mengacu kepada konteks. Tanda kehadiran struktur (teks) bisa ditangkap melalui indra, melalui kedua cara mengada yaitu ucapan (yang dianggap bersifat logosentris) dan teks (yang menjadi cara hadir utama).

\section{Pemikiran Heidegger dan Derrida mengenai Kehadiran di Ruang Digital: Sebuah Konstruksi}

Setelah membaca pemikiran Heidegger dan Derrida, penelitian ini akan mengonstruksi pemikiran keduanya dalam sebuah dialog imajinatif mengenai makna kehadiran dalam ruang digital.

Dalam ruang digital, dan berdasarkan pemikiran Heidegger mengenai metaphysics of presence kita menemukan bahwa setiap subjek (Dasein dalam bahasa Heidegger) harus menyadari mengapa dia ada dalam ruang itu. Bagi Heidegger, subjek yang sesungguhnya adalah subjek yang dapat memahami keterlemparannya, dalam konteks penelitian ini, dalam ruang digital. Jika Heidegger ditanya mengenai makna kehadiran, pertanyaan utama adalah apakah subjek memahami keterlemparannya dalam ruang tersebut, mengapa dan untuk apa dia di situ? Konsekuensinya, kehadiran hanya menjadi riil ketika subjek yang dapat mempertanyakan kehadirannya dan memahami maksud kehadirannya, dalam hal ini ruang digital. Sampai titik ini, subjek hanya bisa memverifikasi kehadirannya dalam ruang digital, namun masih menyisakan pertanyaan mengenai relasi antarsubjek.

Untuk menjawab pertanyaan di atas, pemikiran Derrida mengenai pengenalan akan struktur (teks) yang riil yang dikenali melalui tanda kehadiran memberi sumbangsih penting. Subjek bisa menangkap teks melalui indra yang menangkap kedua cara mengada yaitu ucapan (yang dianggap bersifat logosentris) dan teks (yang menjadi cara hadir utama). Derrida tidak membatasi teks sebagai tulisan, namun sebagai

47 Derrida, Of Grammatology, 40-41. 
representasi kehadiran yang dikenali oleh subjek. Dalam ruang digital, subjek mengenali teks, gambar, suara, dan video sebagai representasi kehadiran subjek yang lain. Kehadiran berarti datangnya bentuk atau tanda objek kepada subjek. Untuk membuat subjek bisa mengenali subjek lainnya, mereka harus bisa saling mengenali tanda kedatangan. Relasi antarsubjek bisa terjadi ketika subjek-subjek mengenali representasi kehadiran yang lain melalui struktur kehadiran mereka dalam ruang tersebut, yaitu teks, gambar, suara, dan video. Pengenalan representasi kehadiran membutuhkan kesadaran subjek yang saling mengenali dirinya dan makna keberadaan dirinya, serta pada saat yang sama mengenali struktur kehadiran (teks) subjek yang lain. Persoalan saat yang sama menjadi krusial dalam pemahaman kehadiran karena menuntut subjeksubjek untuk sama-sama hadir, menyadari keterlemparannya dalam ruang tersebut, dan mengenali subjek lain dalam waktu yang sama.

Melalui konstruksi pemikiran Heidegger dan Derrida, kita menemukan kehadiran antar-subjek dalam ruang digital sebagai subjek-subjek yang dengan sengaja menyadari keterlemparannya dalam sebuah ruang digital, dan mengenal serta memahami kehadiran struktur subjek lain melalui pengenalan yang saling memahami dalam waktu yang sama. Membangun relasi yang bermakna melalui kesadaran antarsubjek yang saling menemukan tanda kehadiran yang lain.

Tanda kehadiran dalam ruang digital adalah teks, gambar, suara, dan video. Ketika subjek saling mengenali kehadiran yang lain melalui tanda kehadiran dalam ruang digital, mereka bisa menyepakati kehadiran satu dengan yang lain. Kehadiran demikian akan kita beri nama kehadiran dengan relasi antarsubjek yang bermakna. Meski demikian, pemikiran Derrida masih harus dikritik atau dipertanyakan untuk mereka dengan disabilitas yang tentu memiliki cara mengenali kehadiran dengan berbeda.

\section{Kesimpulan}

Penelitian di atas berangkat dari sebuah imajinasi konstruktif pemikiran Heidegger dan Derrida dalam menjawab masalah dan makna kehadiran dalam ruang digital menghasilkan definisi kehadiran di ruang digital yang menuntut perjumpaan antarsubjek yang bermakna dengan syarat keterlemparan yang disadari dan relasi antarsubjek yang saling mengenal tanda kehadiran yang lain dalam ruangan tersebut. Beberapa aplikasi teleconference bisa menunjukkan kehadiran yang membuat semua subjek mampu berelasi yaitu berbagai aplikasi video call seperti Zoom, Skype, BlueJeans, Cisco, Google Meet, Facebook Group Call, Whatsapp Video Call, dsb. Namun demikian, kehadiran yang tidak membutuhkan relasi antarsubjek yang bermakna, dalam pemahaman Derrida-teks: penanda kehadiran yang melampaui batas waktu-bisa ditemui dalam aplikasi YouTube, media sosial, dan aplikasi pengantar pesan lainnya. 


\section{Referensi}

Audi, Robert, ed. The Cambridge Dictionary of Philosophy. Second Edi. Cambridge: Cambridge University Press, 1995. https://doi.org/10.5860/choice.33-3059.

Backman, Jussi. Complicated Presence: Heidegger and the Postmetaphysical Unity of Being. SUNY Series in Contemporary Continental Philosophy. Albany, NY: Suny Press, 2015.

Berger, Teresa. "Participatio Actuosa in Cyberspace? Vatican II's Liturgical Vision in a Digital World." Worship 87 (2013): 533-47.

Blobaum, Bernd, ed. Trust and Communication in a Digitized World. Models and Concepts of Trust Research. London; New York: Springer, 2016. http://www.springer.com/it/book/9783319280578.

Bunnin, Nicholas, and Jiyuan Yu. The Blackwell Dictionary of Western Philosophy. Malden, MA ; Oxford, UK: Blackwell Publishing Ltd., 2004. https://doi.org/10.1111/b.9781405106795.2004.00004.x.

Champion, Erik, ed. The Phenomenology of Real and Virtual Places. Abingdon, Oxon: Routledge, 2019. https://doi.org/10.4324/9781315106267-4.

Derrida, Jacques. Limited Inc. Edited by Gerard Graff. Translated by Samuel Weber and Jeffrey Mehlman. Evanston, IL: Northwestern University Press, 1988.

- - - Of Grammatology. Translated by Gayatri Chakravorty Spivak. Corrected. Baltimore, Maryland: The Johns Hopkins University Press, 1976.

- - The Truth in Painting. Translated by Geoff Bennington and Ian McLeod. Chicago; London: The University of Chicago Press, 1987.

- - Writing and Difference. Translated by Alan Bass. London; New York: Routledge, 1978.

_—_. "Living On." Trans. James Hulbert. In Deconstruction and Criticism, ed. Harold Bloom et. al. London; Henley: Routledge \& Kegan Paul, 1979: 75-176

Fried, Gregory. Confronting Heidegger: A Critical Dialogue on Politics and Philosophy. New Heidegger Research. London; New York: Rowman \& Littlefield, 2020.

Harman, Graham. Heidegger Explained: From Phenomenon to Thing. Chicago; La Salle, IL: Open Court, 2007.

Heidegger, Martin. Being and Time. Translated by John Macquarrie and Edward Robinson. Oxford: Basil Blackwell, 1962.

Hope, Erling. "Between God and Google: Reflections on the Technology Project of the Society for the Arts, Religion and Contemporary Culture." CrossCurrents 62, no. 2 (2012): 235-59.

Inwood, Michael. The Blackwell Philosopher Dictionaries: A Heidegger Dictionary. Malden, MA: Blackwell Publishers Ltd., 1999. https://doi.org/10.1036/007137809X.

Olusola, Emmanuel B. "Digital Church and E-Culture in the New Media Age: The Spectrum of Nigeria." African Ecclesial Review 57, no. 3 \& 4 (2015): 206-24.

Panzer, Ryan. “Overcoming Digital Division: Digital Sacramentality as a Source of 
Healing." Journal of Religious Leadership 19, no. 1 (2020): 49-69.

Tritten, Tyler. Beyond Presence: The Late F. W. J. Schelling's Criticism of Metaphysics. Boston; Berlin: De Gruyter, 2012.

Wall, Kevin Hart \& Barbara. The Experience of the Kingdom of God. Edited by Kevin Hart and Barbara E. Wall. Perspectives in Continental Philosophy. New York: Fordham University Press, 2005.

Watts, Michael. Heidegger: A Beginner's Guide. Abingdon, Oxon: Hodder \& Stoughton, 2001.

Zsupan-Jerome, Daniella. "Virtual Presence as Real Presence? Sacramental Theology and Digital Culture in Dialogue.” Worship 89, no. 6 (2015): 526-42. 